\title{
Standardized tuberculosis treatment outcome monitoring in Europe
}

\author{
Recommendations of a Working Group of the World Health Organisation (WHO) and the European \\ Region of the International Union Against Tuberculosis and Lung Disease (IUATLD) for uniform \\ reporting by cohort analysis of treatment outcome in tuberculosis patients
}

\author{
J. Veen*, M. Raviglione+, H.L. Rieder ${ }^{\star}$, G.B. Migliori\#, P. Graf», M. Grzemska+, R. Zalesky\$
}

Standardized tuberculosis treatment outcome monitoring in Europe. J. Veen, M. Raviglione, H.L. Rieder, G.B. Migliori, P. Graf, M. Grzemska, R. Zalesky. (OERS Journals Ltd 1998. ABSTRACT: Consensus-based recommendations have been developed by a Working Group of the World Health Organisation (WHO) and the International Union Against Tuberculosis and Lung Disease (IUATLD) on uniform reporting of tuberculosis (TB) treatment outcome data in countries in Europe. The main purpose of treatment monitoring is to find out how many of the potential infectious TB patients notified were declared cured at the end of treatment. Following the uniform case definitions as defined in 1996, emphasis is placed on cohort analysis of definite cases of pulmonary TB.

The Working Group recommends using a minimal set of six mutually exclusive categories of treatment outcome: cure, treatment completed, failure, death, treatment interrupted, and transfer out. More detailed subsets may be chosen. Treatment outcome is expressed as a percentage of the total number of cases notified. Analysis should be separate for new and retreatment cases. Treatment outcome data have to be collected at the local level and passed on to regional and national authorities on an ongoing basis.

Evaluation of treatment results becomes, preferably, an inbuilt component of national monitoring of programme performance. Because of the long duration of treatment, it is recommended that analysis is carried out in the first quarter of the calendar year that follows a full year after the last patient was enrolled. Feedback is essential. Treatment outcome results should become an inseparable part of the annual report on tuberculosis.

Eur Respir J 1998; 12: 505-510.
*Royal Netherlands Tuberculosis Association (KNCV), The Hague, The Netherlands. +World Health Organisation, Global Tuberculosis Programme (WHO/GTB), Geneva, Switzerland. International Union Against Tuberculosis and Lung Disease (IUATLD), Paris, France. "Fondazione Clinica del Lavoro Care and Research Institute, Tradate, Italy. ${ }^{\S}$ Gesundheitsreferat, München, Germany. \$Latvian Centre of Tuberculosis and Lung Diseases, Riga, Latvia.

Correspondence: J. Veen

Royal Netherlands Tuberculosis Association (KNCV)

P.O. Box 146, 2501 CC The Hague

The Netherlands

Fax: 31703584004

Keywords: Cohort analysis

Europe

Surveillance

treatment

tuberculosis

Received: January 301998

Accepted after revision April 181998
The resurgence of tuberculosis (TB) in recent years in many industrialized countries [1-7] has shown that the disease occurs frequently in specific groups, such as foreign-born persons from countries with a high prevalence, intravenous drug users and socially marginalized people. In some of these groups there is an additional risk for human immunodeficiency virus (HIV) infection or antiTB drug resistance [8]. The reasons for the resurgence of TB in central and eastern Europe are not entirely clear, as $\mathrm{HIV}$ is not widespread in the area and immigration from high-prevalence countries does not seem to be an issue. Possible causes are a rapid increase in poverty, poor living conditions with overcrowding, war, malnutrition, lack of drugs, the chronic problem of underfunding of National Tuberculosis Programmes (NTPs) and nonadherence to programme policies. These factors may contribute to increased transmission of Mycobacterium tuberculosis in the community and/or to an increased risk of progression from latent to overt clinical TB. Elaborated recommendations for standardized reporting of TB cases in Europe, including a common case definition and minimum information to be reported on each case have been published [9].
Early diagnosis and adequate treatment of infectious patients with pulmonary TB are necessary to reduce transmission of $M$. tuberculosis and ultimately to achieve elimination of TB. The World Health Organisation (WHO) defines an effective NTP as having a high cure rate, a low level of acquired drug resistance and a high case detection rate [10].

The successful treatment of patients depends on the susceptibility of the bacterial strain to anti-TB drugs, the regimen employed and its duration, the availability of drugs and the adherence of both treatment provider and patient to recommended standards of care. Acquired drug resistance, i.e. resistance in a strain isolated from a patient with a history of previous treatment, is the consequence of noncompliance by either physician or patient, or erratic availability of drugs. Cure is achieved by an adequate treatment regimen, based on a properly selected combination of drugs, with the correct dosage for a sufficient duration [11]. The efficacy of modern treatment regimens is well established under controlled trial conditions, but very few data on treatment effectiveness under routine conditions in low-incidence countries are available [12]. 
Monitoring the outcome of treatment is essential in order to evaluate the effectiveness of the intervention. For case notification, 37 European countries agreed on a standardized minimum set of data to be collected, which is now being implemented in all 51 countries of the WHO Europe region [9]. Reliable case notification systems are available in most European countries, but only a few have reliable information on the results of treatment.

Outcome indicators must be defined and may be based on the experience in low-income countries [13] and in some low-incidence countries which have recently introduced treatment monitoring. Data collection, analysis and interpretation of treatment outcome allow more focused intervention and contribute to improved quality of care. To allow international comparison, monitoring should be standardized.

Results are important for public health, but are also of great interest for the clinician, who needs to know how successful the prescribed treatment is in each individual patient. This common interest requires the clinician to report the outcome of treatment on a voluntary basis to public health authorities. It is equally important that the public health structure provides feedback based on these reports. While in the majority of European countries notification of diagnosed cases is mandatory, the evaluation of treatment outcome is not. Countries need to implement standard recommendations to make treatment outcome evaluation possible. Good communication between the curative and preventive services is therefore necessary.

In 1997 a WHO/International Union Against Tuberculosis and Lung Disease (IUATLD) Working Group on Standardized Tuberculosis Treatment Monitoring in Europe was established. Its main objective was to produce a consensus document on recommendations for TB treatment monitoring in Europe with agreed definitions and procedures. During the Third European Workshop on Tuberculosis Control, held in the Netherlands, the recommendations of this Working Group were adopted by the representatives of 39 countries.

The present paper includes a minimum set of outcome parameters, which can be extended to fit the needs of individual countries.

\section{Review of current systems of treatment monitoring}

Experience from low-income countries shows that cohort analysis of treatment outcome is a feasible and crucial undertaking. Reliable results of treatment are today available from at least 70 countries which have adopted the recording and reporting system recommended by the WHO and the IUATLD [14, 15]. Table 1 shows results from some European countries which have adopted such, or a similar system.

\section{Objective of standardized treatment monitoring}

The main purpose of treatment monitoring is to find out how many of the potentially infectious TB patients notified were declared cured at the end of treatment. Thus the effectiveness of the treatment delivery process can be evaluated and a timely change of strategy within a NTP can be made if results under field conditions prove not to be as good as expected. In addition, standardized treatment monitoring allows comparisons both within and between countries.

Treatment outcome depends on an effective regimen, such as the WHO and IUATLD-recommended short-course regimens. A short-course chemotherapy (SCC) regimen is a regimen lasting for 9 months or less, containing rifampicin during at least the initial 2 months of treatment. SCC has been proven to be effective under both trial [24] and operational [25] conditions. Adaptation of these regimens is possible depending on national recommendations. In order to ensure compliance, the WHO and IUATLD promote the use of directly observed therapy (DOT) during at least the first 2 months of treatment, in which patients take drugs under the direct observation of healthcare providers.

\section{Definitions}

Cases

A Working Group report on surveillance of $\mathrm{TB}$ in Europe defined two groups of patients: definite cases and other than definite cases. A definite case of TB is a patient with culture-confirmed disease due to M. tuberculosis

Table 1. - Some low-incidence countries in Europe with treatment outcome results, method of collection, year of collection, size of the cohort and percentage of successful outcome

\begin{tabular}{|c|c|c|c|c|c|}
\hline Country & Year(s) & $\begin{array}{c}\text { Patients } \\
n\end{array}$ & $\begin{array}{c}\text { Cured/completed } \\
\%\end{array}$ & $\begin{array}{l}\text { Data } \\
\text { collection }\end{array}$ & Reference \\
\hline Czech Republic & 1994 & 509 & 53 & Surveillance & [16] \\
\hline \multicolumn{6}{|l|}{ France } \\
\hline Paris & 1992 & 122 & 66 & Survey & [17] \\
\hline Germany & 1994-1995 & 1000 & 68 & Survey & $*$ \\
\hline Israel & $1990-1992$ & 877 & 54 & Survey & {$[18]$} \\
\hline Italy & 1995-1996 & 1120 & 83 & Survey & [19] \\
\hline Netherlands & 1995 & 1469 & 82 & Surveillance & [20] \\
\hline Norway & 1995 & 101 & 77 & Surveillance & + \\
\hline \multicolumn{6}{|c|}{ Russian Federation } \\
\hline Ivanova & 1995 & 119 & 71 & Survey & \# \\
\hline Slovakia & 1994 & 421 & 81 & Surveillance & {$[16]$} \\
\hline \multicolumn{6}{|l|}{ Switzerland } \\
\hline Vaud & 1988-1992 & 120 & 63 & Survey & {$[21]$} \\
\hline Zurich & 1991-1993 & 428 & 73 & Survey & [22] \\
\hline Turkey & 1990 & 404 & 15 & Survey & [23] \\
\hline
\end{tabular}

*: M. Forssbohm, written communication, 1997; +: E. Heldal, written communication, 1997; \#: M. Ambrossetti and coworkers, unpublished report, 1997. 
complex. In countries where level II laboratories [26] are not routinely available or where the routine culturing of specimens from all cases cannot be afforded or expected, a patient with two consecutive sputum smear examinations positive for acid-fast bacilli (AFB) is also considered to be a "definite" case. Other than definite cases are cases without bacteriological confirmation, where clinical judgement leads to the decision to treat the patient with a full course of antituberculous therapy [9].

Both definite and other than definite cases are notifiable. Assessment of treatment outcome of definite cases with pulmonary TB has the highest priority, because this group has confirmed $\mathrm{TB}$, is amenable to bacteriological follow-up examination and encompasses those cases that are potential transmitters of tubercle bacilli in the community.

To monitor treatment outcome the cohort of patients to be evaluated has to be defined. Cases with no prior treatment (new cases) and cases with previous treatment (retreatment and chronic cases) must be clearly separated.

\section{Cohort}

A cohort is a designated group of people who are followed or traced over a period of time. A cohort can be stratified by type of disease, geographic provenance, age, sex or other determinants.

For the surveillance of TB in Europe the cohort of patients whose outcome is to be analysed consists of patients with definite pulmonary TB, who were notified during one defined calendar year and living within the borders of a country.

Stratification is essential to separate new and previously treated patients, but optional for other characteristics.

\section{Cohort analysis}

In $\mathrm{TB}$ control, the term cohort analysis refers to the analysis of treatment outcome in a cohort of patients who were notified during a designated period and whose treatment outcome was analysed at a point in time at which they were anticipated to have completed their course of treatment. All notified cases of that particular cohort constitute the denominator for analysis. Patients who were diagnosed and notified, but never started treatment, must be included in the denominator. This includes cases diagnosed post mortem.
Treatment outcome may be evaluated by various categories. WHO and IUATLD use an agreed set of six possible and mutually exclusive categories of treatment outcome in high-incidence countries. These categories are cure, treatment completed, failure, death, treatment interrupted, and transfer out (table 2) [13, 14]. The same six categories should be used in low-incidence countries, although more detailed subsets may be chosen. Treatment outcome is usually expressed as a percentage of the total number of notified cases.

\section{Treatment outcome}

Cure. A patient is considered cured if he or she has completed a full course of anti-TB therapy and a) if the diagnosis was confirmed by culture, there is, on at least one occasion, a documented conversion (culture negative) during the continuation phase; or b) if the diagnosis was based on microscopy, there is documented evidence of two negative sputum smears during the continuation phase, one of which must be at the end of treatment.

Treatment completed. A patient who was notified as a definite case is defined as having completed treatment if the course of treatment prescribed was completed and if the patient was officially discharged by the attending physician, but in whom a) when the diagnosis was confirmed by culture, no bacteriological conversion has been documented, or b) when the diagnosis was based on microscopy, no smear result is available at the end of treatment.

Treatment failure. A patient who fails to achieve bacteriological conversion within 5 months after the start of treatment or, after previous conversion, becomes sputum smear or culture positive again, and in whom the first-line treatment is replaced by second-line treatment, should be considered a failure case. Ideally, the registration card of such a patient should be closed, treatment outcome reported as failure and for continuation of treatment the patient should be re-registered as a patient who has been treated previously.

Death. A patient who died of any cause during the course of treatment is recorded under death. In most countries in Europe it is desirable to separate death from $\mathrm{TB}$ from death with TB, i.e. due to other causes. A patient who died with tuberculosis but never started treatment (diagnosis at post mortem) needs to be notified and should be included in the denominator when treatment outcome is evaluated.

Table 2. - Definitions

\begin{tabular}{|c|c|c|}
\hline & \multicolumn{2}{|c|}{ Definite case with pulmonary tuberculosis } \\
\hline & Culture confirmed & Sputum smear microscopy confirmed \\
\hline Cured & $\begin{array}{l}\text { Documented conversion of culture during the } \\
\text { continuation phase }\end{array}$ & $\begin{array}{l}\text { Sputum smears negative on two occasions at the end } \\
\text { of treatment }\end{array}$ \\
\hline $\begin{array}{l}\text { Treatment } \\
\text { completed }\end{array}$ & $\begin{array}{l}\text { Documented treatment completion, but no } \\
\text { documented culture conversion }\end{array}$ & $\begin{array}{l}\text { Documented treatment completion, but not sputum } \\
\text { smear microscopy available at the end of treatment }\end{array}$ \\
\hline $\begin{array}{l}\text { Treatment } \\
\text { failure }\end{array}$ & $\begin{array}{l}\text { Culture remaining or again becoming positive } \\
\text { at } 5 \text { months of treatment or later }\end{array}$ & $\begin{array}{l}\text { Sputum smears remaining or becoming again positive } \\
\text { at } 5 \text { months of treatment or later }\end{array}$ \\
\hline Death & $\begin{array}{l}\text { Death of the patient irrespective of cause at any } \\
\text { time before envisaged end of treatment }\end{array}$ & $\begin{array}{l}\text { Death of the patient irrespective of cause at any time } \\
\text { before envisaged end of treatment }\end{array}$ \\
\hline $\begin{array}{l}\text { Treatment } \\
\text { interrupted }\end{array}$ & $\begin{array}{l}\text { Patient off treatment for } 2 \text { consecutive months } \\
\text { or more or failure to complete treatment within } 9 \\
\text { months for a } 6 \text {-month or within } 12 \text { months for a } \\
\text { 9-month regimen or drug intake }<80 \%\end{array}$ & $\begin{array}{l}\text { Patient off treatment for } 2 \text { consecutive months or } \\
\text { more or failure to complete treatment within } 9 \\
\text { months for a } 6 \text {-month or within } 12 \text { months for a } \\
\text { 9-month regimen, or drug intake }<80 \%\end{array}$ \\
\hline Transfer out & $\begin{array}{l}\text { A patient referred to another clinician for } \\
\text { treatment in whom information on treatment } \\
\text { outcome cannot be obtained }\end{array}$ & $\begin{array}{l}\text { A patient referred to another clinician for treatment } \\
\text { in whom information on treatment outcome cannot } \\
\text { be obtained }\end{array}$ \\
\hline
\end{tabular}


Treatment interrupted (default). If the patient interrupts treatment for any reason, this is recorded as treatment interrupted [10]. To be classified as such, interruption of treatment should be for $>2$ months, noncompletion of treatment within 9 months if placed on a 6 month regimen or within 12 months for an 8 or 9 month regimen, or if the drug intake was $<80 \%$ of the prescribed dose. Prolonged interruption of treatment, caused by serious adverse effects to the drugs, is also recorded under this heading.

The registration card of such a patient should be closed, treatment outcome reported as treatment interrupted, and for continuation of treatment the patient should be re-registered as a patient who has been treated before.

Transfer out. Some patients may continue treatment at another treatment centre during the course of treatment. In low-incidence countries, with a proper infrastructure, information on transferred patients should be actively collected by health authorities. Where it is known that the patient moved, but no additional information is available, this should be recorded as transfer out.

\section{Retreatment case}

Patients who have been treated in the past are considered retreatment cases. The treatment outcome of retreatment cases is likely to be different from that of new cases. Therefore, these patients must be identified clearly and evaluated separately. Retreatment cases include: failure cases (see above); treatment interrupted cases (see above); and relapse cases, i.e. patients who were previously treated for $\mathrm{TB}$ and declared cured before becoming once again a definite case of pulmonary TB.

\section{Chronic case}

A chronic case is a patient who fails on a full-course retreatment therapy. This is not a frequent event with modern effective treatment regimens, but some patients who continue to interrupt treatment or harbour resistant strains may become chronic excretors of bacilli.

This often results in a long duration of treatment, which prohibits inclusion in the treatment monitoring database. These cases should be reported separately. To deal with this problem some countries evaluate the patient's progress 12 months after the start of treatment, adding "Still on treatment" as an additional outcome category.

\section{Flow of information}

As with the notification of cases, treatment outcome data have to be collected at the local level and passed on to regional and national authorities on an ongoing basis. No country in Europe (except for Norway, which started mandatory outcome reporting on January 1, 1997) has made reporting on treatment outcome mandatory and, therefore, completeness of information depends both on the public health system and on the voluntary cooperation of those who treat the patients, who are, in many countries, clinicians operating outside the public health domain.

In central and eastern Europe, case finding and treatment are still mainly part of the public health domain and information may be readily available [5]. In contrast, in many countries in western Europe there is no regular flow of information between the two systems. The long duration of treatment necessitates the development of a "signa- lling" system to collect information on treatment outcome after a standardized period. Poorly responding or drugresistant cases may be treated well beyond the normal standardized period. A signal should also provide for these cases. Such a signal could be an automatic request for treatment information 15 months after the date of registration. Operational difficulties could limit the completeness of information on the cohort of patients to be evaluated.

In countries where the public health authorities are involved in the treatment of patients it is easier to collect more detailed information on the course of treatment and its outcome.

Evaluation of treatment results preferably becomes an inbuilt component of national monitoring of programme performance. As defined above, the cohort of patients selected for analysis consists of patients with definite pulmonary TB, notified during one defined calendar year. Because envisaged treatment with short-course chemotherapy lasts for up to 9 months and patients are allowed to interrupt treatment for up to 2 months before being classified as such, analysis of treatment outcome can only take place $1 \mathrm{yr}$ after closure of the calendar year of notification. It is, thus, recommended that analysis is conducted in the first quarter of the calendar year that follows a full year after the last patient was enrolled.

Treatment outcome results must be linked to the notification. Therefore, reporting to the first level of collection should be nominal, after which a coded identifier may replace the name of the patient.

If the first level of collection only reports aggregated data, treatment outcome cannot be linked to the notified case at the higher level. Occasional surveys at the local level could then provide limited data.

Any additional information needed for the analysis of a specific cohort, which is not included in the case notification, must be collected at the time of treatment outcome reporting. Since this information has to be collected from clinicians, the request for information should be concise and easy to answer. An example of a form to introduce a system of active data collection is given in Appendix 1.

\section{Analysis and reporting}

Data should be analysed by calendar year. Proportions should be based on the number of cases notified in that particular year.

Validity of reported data should be part of the analysis. Several indicators can be used to evaluate reported data, including completeness of information, mistakes and delay of invoice [27].

In some countries it is possible to obtain extra information to evaluate the outcome in specific risk groups or in patients with specific risk factors. This can be seen as an optional extension of the monitoring system. The type of stratification used for cohort analysis will depend on the type of variables that were collected at notification and the completeness of information on these variables. Dual infection with HIV and the presence of multidrug-resistant TB are included among risk factors.

Compliance with timely information procedures depends on regular feedback of analysis and interpretation to those who provided the data. Dissemination of information should also include policy makers. Case finding reports should appear annually. Treatment outcome results 
should become an inseparable part of that report, even though they will always refer to cases reported $1 \mathrm{yr}$ earlier.

The results of the analysis may be summarized as: successful outcome, the percentage of patients who were cured or completed treatment out of all notified; death, the percentage of patients who died before the diagnosis was established or died during the course of treatment either with or from TB, out of all notified; and potentially unsatisfactory outcome, the percentage of patients who interrupted treatment, were transferred out or failed treatment, out of all notified.

Surveillance should result in public health action. The WHO's global target for infectious cases is a cure rate of $85 \%$. If a $5 \%$ death rate is accepted as unavoidable, the maximum rate of unsatisfactory outcome is $10 \%$. This means that if this unsatisfactory outcome rate is $>10 \%$ the NTP should investigate the reasons and develop intervention methods to improve the situation.

\section{Implementation of treatment outcome monitoring}

Reporting on treatment results is not mandatory in lowincidence countries, with the exception of Norway. Only a few countries so far have introduced a monitoring system.

Now that consensus on standardized treatment monitoring has been reached, a system within countries must be developed. Physicians must be persuaded to record the treatment outcome of individual patients in a standardized way and report regularly to the central level, where a database has to be established. Each country has to define its own approach, involving government officials, professional associations and experts. Attention must be given to ethical and legal aspects regarding patient confidentiality. Funds must be made available for investments, personnel and running costs. By doing so the national tuberculosis control programmes provide inbuilt quality control for treatment delivery and programme performance.

Members of the Working Group: Albania: J. Bushati, A. Hafizi; Armenia: M. Safarian; Austria: J.P. Klein, B. Schmidgruber; Azerbeidian: A. Umnyashkin: Belarus: V Borschevsky; Belgium: M. Uydebrouck, M. Wanlin; Bosnia: Z. Disdarevic, B. Stefanovic; Bulgaria: D.I. Stephanova; Croatia: I. Gjenero-Margan; Czech Republic: L. Trinka; Finland: R. Ruohonen, P. Ruutu, E. Tala; France: V. Schwoebel; Germany: M. Forssbohm, G. Rasch, R. Loddenkemper; Georgia: G. Khechinashvili; Greece: N. Yatromanolakis; Hungary: D. Kozma; Ireland: L. Clancy; Israel: D. Chemtob; Italy: M.L. Moro; Kyrghyzstan: A.S. Alisherov; Latvia: J. Leimans; Lithuania: K. Miskinis, D.S. Gaidamoniene; Macedonia: S. Talevski; Malta: A Galea-Baron; Moldava: D.O. Sain; The Netherlands: N.A. Kalisvaart, C.S.B. Lambregts-van Weezenbeek, K. Styblo; Norway: E. Heldal; Portugal: M.L. Antunes-Pereira; Romania: E. Corlan; Russian Federation: A.G. Khomenko, A. Priymak; Scotland: D.H. Clark, P. Christie; Slovenia: J. Sorli; Slovakia: P. Kristufek; Spain: M. Diez; Sweden: V. Romanus; Switzerland: J.P. Zellweger; Turkey: S. Ozkara; UK: J. Leese, J. Watson, F. Drobniewski; Yugoslav Republic: D. Popovac.

\section{References}

1. Raviglione MC, Sudre P, Rieder HL, Spinaci S, Kochi A. Secular trends of tuberculosis in Western Europe. Bull WHO 1993; 71: 297-306.

2. Cantwell MF, Snider DE Jr, Cauthen GM, Onorato IM. Epidemiology of tuberculosis in the United States, 1985 through 1992. JAMA 1994; 272: 535-539.

3. Bhatti N, Law MR, Morris JK, Halliday R, Moore-Gillon $\mathrm{J}$. Increasing incidence of tuberculosis in England and Wales: a study of the likely causes. BMJ 1995; 310: 967969.
4. Hubert B, Desenclos JC, Schwoebel V. Epidémiologie actuelle de la tuberculose. Rev Tuberc 1995; 1: 7-17.

5. Raviglione MC, Rieder HL, Styblo K, Khomenko AG, Esteves K, Kochi A. Tuberculosis trends in eastern Europe and the former USSR. WHO Chronicle 1994; 176: 1-34.

6. Vall Mayans M, Maguire A, Miret M, Alcaide J, Parrón I, Casabona J. The spread of AIDS and the re-emergence of tuberculosis in Catalonia, Spain. AIDS 1997; 11: 499-505.

7. Zalesky R, Leimans J, Pavlovska I. The epidemiology of tuberculosis in Latvia. Monaldi Arch Chest Dis 1997; 52: 142-146.

8. Brudney K, Dobkin J. Resurgent tuberculosis in New York City. Human immunodeficiency virus, homelessness and the decline of tuberculosis control programs. Am Rev Respir Dis 1991; 144: 745-749.

9. Rieder HL, Watson JM, Raviglione MC, et al. Surveillance of tuberculosis in Europe. Eur Respir J 1996; 9: 1097-1104.

10. World Health Organisation. Treatment of tuberculosis. Guidelines for National Programmes. 2nd Edn. Geneva, World Health Organisation, 1997.

11. Crofton J, Horne N, Miller F. Clinical tuberculosis. London, MacMillan Education, 1992.

12. Clancy L, Rieder HL, Enarson DA, Spinaci S. Tuberculosis elimination in the countries of Europe and other industrialised countries. Eur Respir J 1991; 4: 1288-1295.

13. International Union Against Tuberculosis and Lung Disease. Tuberculosis guide for low income countries, 4th Edn. Paris, IUATLD, 1996.

14. World Health Organisation. Framework for effective tuberculosis control. Geneva, World Health Organisation, 1994.

15. Enarson DA. Principles of IUATLD collaborative tuberculosis programmes. Bull IUATLD 1991; 66: 195-200.

16. World Health Organisation/Global Tuberculosis Programme. Global tuberculosis control. Geneva, WHO Report, WHO/TB/97.225, 1997.

17. Cruz AG, Gulbaran Z, Enarson DA. Cohort evaluation of treatment results, Paris. Tuberc Lung Dis 1995; 76: Suppl. 2,80 .

18. Chemtob D, Weiler-Ravell D, Slater PE, Epstein L. Completion of tuberculosis treatment in Israel, 1990-92. Tuberc Lung Dis 1996; 77: Suppl. 2, 73-74.

19. Migliori GB, Ambrosetti M, Besozzi G, et al. Cohort analysis of anti-tuberculosis treatment results in Italy. Progress Report, First Research Project Tuberculosis, Istituto Superiore di sanit B. Rapporti ISTSAN 1997; 97: 141.

20. Netherlands Tuberculosis Register. Index tuberculosis 1996. Den Haag, KNCV, 1997.

21. Coulon P, Zellweger JP. Outcome of patients treated for pulmonary tuberculosis in Vaud County. Tuberc Lung Dis 1995; 76: Suppl. 2, 79-80.

22. Rose N, Shang H, Pfyffer GE, Brändli O. Tuberkulose therapie im Kanton Zürich 1991-1993: was sind die Ursachen für Rezidive und Therapieversagen. Schweiz Med Wochenschr 1996; 126: 2059-2067.

23. Kocabas A, Burgut R, Kibaroglu E, et al. Fate of smear positive pulmonary tuberculosis patients in Turkey. Tuberc Lung Dis 1995; 76: Suppl. 2, 79.

24. Fox W. Whither short-course chemotherapy? Br J Dis Chest 1981; 75: 331-357.

25. Nkinda SJ, Willemsen FMG, Styblo K. Tuberculosis control, including short-course chemotherapy in the context of the mutual assistance programme of the IUAT. Bull IUATLD 1986; 61: 10-13.

26. European Society for Mycobacteriology. Groothuis DG, Yates MD, eds. Diagnostic and public health mycobacteriology. 2nd Edn. London, Bureau of Hygiene and Tropical Diseases, 1991.

27. Centers for Disease Control. Guidelines for evaluating surveillance systems. Morb Mort Wkly Rep 1988; 37: Suppl. 5, 1-18. 


\section{Appendix: Minimum information on treatment outcome reporting form}

Name and

address of patient

for confidentiality reasons this may be replaced by the patient identifier as given at the time of notification (Notification Form)

Name and

Date of notification

address of reporting physician

(DD/MM/YYYY)

Telephone number

Postal code of patient

residence at time of notification

Date of birth (DD/MM/YYYY)

Country of birth

Sex

( ) Male

( ) Female

or Patient identifier to link with Tuberculosis Case Reporting Form

Diagnosis:

$$
\begin{aligned}
& \text { ( ) Definite case } \\
& \text { ( ) Other than definite case }
\end{aligned}
$$

( ) New case

( ) Retreatment case

Information on treatment

Date treatment started

(DD/MM/YYYY)

Date treatment ended

(DD/MM/YYYY)

(or in case of interruption date of last contact with the patient, or in case of death date of death)

Change of treatment from first line to second line treatment:

( ) Yes

( ) No

Treatment outcome
( ) Cure
( ) Failure
( ) Treatment interrupted
( ) Treatment completed
( ) Death
( ) Transfer out 